\title{
Article \\ Extraction of Polyphenols from Olive Leaves Employing Deep Eutectic Solvents: The Application of Chemometrics to a Quantitative Study on Antioxidant Compounds
}

\author{
Hamida Akli ${ }^{1,2}$, Spyros Grigorakis ${ }^{1}$, Abdessamie Kellil ${ }^{1}{ }^{\mathbb{D}}$, Sofia Loupassaki ${ }^{1}$, Dimitris P. Makris ${ }^{3} \mathbb{D}^{\mathbb{D}}$, \\ Antony Calokerinos ${ }^{4}$ (D) Abderrahmane Mati ${ }^{2}$ and Nikos Lydakis-Simantiris ${ }^{5,6, * \mathbb{D}}$
}

check for updates

Citation: Akli, H.; Grigorakis, S.; Kellil, A.; Loupassaki, S.; Makris, D.P.; Calokerinos, A.; Mati, A.;

Lydakis-Simantiris, N. Extraction of Polyphenols from Olive Leaves Employing Deep Eutectic Solvents: The Application of Chemometrics to a Quantitative Study on Antioxidant Compounds. Appl. Sci. 2022, 12, 831. https://doi.org/10.3390/app 12020831

Academic Editor:

Alessandra Durazzo

Received: 1 October 2021

Accepted: 15 December 2021

Published: 14 January 2022

Publisher's Note: MDPI stays neutral with regard to jurisdictional claims in published maps and institutional affiliations.

Copyright: (C) 2022 by the authors. Licensee MDPI, Basel, Switzerland. This article is an open access article distributed under the terms and conditions of the Creative Commons Attribution (CC BY) license (https:// creativecommons.org/licenses/by/ $4.0 /)$.
1 Food Quality \& Chemistry of Natural Products, Mediterranean Agronomic Institute of Chania, International Centre for Advanced Mediterranean Agronomic Studies, P.O. Box 85, 73100 Chania, Greece; hakli.aklih@gmail.com (H.A.); grigorakis@maich.gr (S.G.); kellilabdessamie@gmail.com (A.K.); sofia@maich.gr (S.L.)

2 Analytical Biochemistry and Biotechnologies Research Laboratory (LABAB), Mouloud Mammeri University, Tizi Ouzou 15000, Algeria; mati_bio@yahoo.com

3 Green Processes \& Biorefinery Group, School of Agricultural Sciences, University of Thessaly, N. Temponera Street, 43100 Karditsa, Greece; dimitrismakris@uth.gr

4 Department of Chemistry, National and Kapodistrian University of Athens, 15772 Athens, Greece; calokerinos@chem.uoa.gr

5 Hellenic Mediterranean University Research Center, Institute of Agri-Food and Life Sciences, 71410 Heraklion, Greece

6 Department of Agriculture, Hellenic Mediterranean University, 71410 Heraklion, Greece

* Correspondence: lydakis@hmu.gr

\begin{abstract}
The extraction of phenolic compounds from olive leaves was optimized using three glycerolbased deep eutectic solvents (DESs) with lysine, proline, and arginine. A three-level Box-Behnken design was used to examine the influence of the liquid/solid ratio, concentration of DESs, and extraction temperature on the yield of the extraction process. A second-order polynomial model was used for predicting the polyphenol extraction yield. The optimal predicted conditions were used for extractions and they provided the highest total phenol yields with the glycerol-lysine exhibiting the best performance. Quantification of tyrosol, hydroxytyrosol, oleuropein, luteolin-7-O-glucoside, and rutin in the extracts showed high content in tyrosol in all DESs, particularly with glycerol-lysine and relatively similar contents with other studies for the other phenolic compounds. Finally, a linear relationship between tyrosol content and the total phenolic content of the extracts was observed.
\end{abstract}

Keywords: deep eutectic solvents; extraction; polyphenols; olive leaves

\section{Introduction}

Food industries generate considerable quantities of wastes or by-products during food processing [1]. Nowadays, one of the major concerns for the food industry is the proper management of waste [2]. An appropriate waste management strategy should necessarily consider sustainable development [3]. The suggested waste hierarchies firstly prioritize the prevention of waste production and secondly the management of waste by reusing, recycling, or recovering processes [4]. Numerous investigations have used recovery technologies as a management strategy due to the high potential of food industry by-products in pharmaceuticals, cosmetics, and food production [5,6]. In recent years, there is, on the one hand, a high demand worldwide for natural ingredients instead of chemical substances, and on the other hand, a growing interest to limit food industry waste in order to protect the ecosystem. This double interest encourages, furthermore, the management of valuable components contained in different sources of food waste.

Olive leaves (OLLs) are the by-product of the olive oil industry. A large amount of OLLs is engendered every year by pruning [7]. OLLs abound with bioactive natural 
products such as phenolic compounds, which exhibit a broad spectrum of bioactivities, including antioxidant, anti-inflammatory, antimicrobial, antihypertensive, hypoglycemic, cardioprotective activities, etc. [8]. A beneficial effect on oxidative stress-based diseases has been observed with the intake of polyphenols [9]. Several investigations have been conducted to elucidate the mechanism of lipid peroxidation and to develop antioxidants to neutralize cell oxidation in order to prevent food deterioration and biological damages [10]. Currently, a safe alternative to synthetic antioxidants is being a major interest of research [11]. As a consequence, numerous natural sources (aromatic plants, fruits, vegetables, leaves, and spices) have been tested for their antioxidant activity, and OLL is one of these resources [12].

The yield and composition of phenols originated from different resources were found to vary depending on some factors related to the extraction solvent and the operating conditions [13] and also on some other factors associated with the genetic background of the plant $[9,14,15]$. OLL phenols are mainly extracted using conventional solvents. However, recently, a move toward green methodologies under the name of green solvents, including ionic liquids (ILs) and deep eutectic solvents (DESs) or low-transition temperature mixtures (LTTMs), has emerged [16-18]. These new solvents aim at maximizing extraction efficiency and reaching new purposes such as researcher safety, environmental protection, and the use of a simplified and cheaper extraction procedure [19]. Due to the physicochemical properties of the green solvents (viscosity, density, hydrophilicity, and solubility), the drawbacks of the conventional solvents are overcome. Furthermore, because of their lower cost, DESs are particularly more attractive solvents, compared with the ILs. The DESs are known as a new class of solvents, alternative to ILs, that consists of a mixture of organic compounds with a melting point lower than that of either individual component [20].

The present work was carried out to optimize OLL polyphenol extraction conditions using DESs based on glycerol, which represents a cheap and biodegradable source material combined with amino acids: lysine, proline, and arginine. A response surface methodology (Box-Behnken design) was implemented in order to assess the effects of the liquid-to-solid ratio $\left(R_{L / S}\right)$, the concentration of DES $\left(C_{\mathrm{DES}}\right)$, and the extraction temperature $(T)$ on the yield in total phenols $\left(Y_{T P}\right)$. This work also aimed at comparing extraction efficiency among the DESs tested and conventional solvents, in addition to obtaining information regarding the selectivity of the DESs tested and the polyphenolic composition of the extracts.

\section{Materials and Methods}

\subsection{Chemicals}

Glycerol (99.5\%) was from Penta. Arginine (>98\%) was from Acros Organic. Lysine $(>98 \%)$ and proline $(>99 \%)$, hydroxytyrosol $(>98 \%)$, tyrosol $(98 \%)$, oleuropein $(>98 \%)$, sodium carbonate, and gallic acid were from Sigma-Aldrich. Rutin $(\geq 99 \%)$ and luteolin-7O-glucoside $(\geq 98 \%)$ were from Extrasynthese. Folin Ciocalteu phenol reagent was from Fluka. All solvents (methanol ( $\geq 99.9 \%$, water) used for chromatographic purposes were HPLC grade and supplied by Honeywell Riedel-de Haen.

\subsection{Plant Material}

Olive leaves of Olea europaea L. (Koroneiki variety) were collected by hand from the garden of the Mediterranean Agronomic Institute of Chania, Greece. The leaves were dried in the oven at $50{ }^{\circ} \mathrm{C}$ for $24 \mathrm{~h}$ until stable mass, subsequently they were ground in a simple blender and sieved to yield a powder with a particle size less than 180 microns. The powder was stored in a stoppered glass vial at room temperature, in the dark, until used.

\subsection{Synthesis of DES}

DESs were synthesized following standard procedures, as described in [21]. Glycerol (hydrogen bond donor, HBD) was mixed with each amino acid (lysine, proline, and arginine), which served as a hydrogen bond acceptor (HBA), at different molar ratios $\left(\mathrm{R}_{\mathrm{mol}}^{\mathrm{D} / \mathrm{A}}\right)$ in order to reach the optimum HBD:HBA ratio. The mixtures were heated at $70{ }^{\circ} \mathrm{C}$ under 
stirring (500 rpm) until the formation of a perfectly transparent liquid. DESs were stored in sealed glass vials in the dark, at room temperature. DESs were checked frequently for their stability or crystal formation during a period of at least one month.

\subsection{Process Optimization and Batch Extraction Procedure}

A response surface methodology [22] was employed by implementing a Box-Behnken design (BBD) to investigate the effect of $R_{\mathrm{L} / \mathrm{S}}, C_{\mathrm{DES}}$, and $T$ on the yield of total polyphenols extraction. The levels of the selected independent variables $R_{L / S}, C_{\mathrm{DES}}, T$ designated $X_{1}$, $X_{2}, X_{3}$, respectively, are analytically presented in Table 1 . The variables were coded at three levels -1 (lower limit), 0 (midrange), and +1 (upper limit), based on the following equation [22]:

$$
x_{i}=\frac{X_{i}-X_{0}}{\Delta X_{i}}, I=1,2,3
$$

where $x_{i}$ and $X_{i}$ represent the dimensionless and the actual value of the variable $i . X_{0}$ is the actual value of the variable $i$ in the central point of the design, and $\Delta X_{i}$ is the variation between the actual value in the central point and the actual value in the upper or lower level of the variable.

The range of the values for the three variables was chosen on the basis of literature data, and the $Y_{T P}$ was the response of interest. Analysis of variance (ANOVA) was used to assess the statistical significance of the obtained mathematical models. Additionally, the desirability function optimization approach was applied to determine the optimum variable setting that would meet the overall desirability of the $Y_{T P}$.

The fitted models were subjected to the lack of fit test, which was used to determine whether the models were adequate to describe the observed data [23]. The coefficient of determination $\left(\mathrm{r}^{2}\right)$ was also determined for the model to indicate the percentage of the variability of the optimization parameter explained by the model. A value of $\mathrm{r}^{2}$ closer to unity shows a better predictive power of the model [24]. Furthermore, the validity of the mathematical model is determined by the closeness of the measured value obtained under optimum conditions to the predicted value of the developed model [25].

Table 1. The values of the independent variables used for the experimental design.

\begin{tabular}{ccccc}
\hline $\begin{array}{c}\text { Independent } \\
\text { Variables }\end{array}$ & Code Units & $\mathbf{- 1}$ & Coded Variable Level & $\mathbf{+ 1}$ \\
\hline$R_{L / S}\left(\mathrm{~mL} \mathrm{~g}^{-1}\right)$ & $X_{1}$ & 50 & $\mathbf{0}$ & 150 \\
$C_{\mathrm{DES}}(\%, w / v)$ & $X_{2}$ & 60 & 75 & 90 \\
$T\left({ }^{\circ} \mathrm{C}\right)$ & $X_{3}$ & 40 & 60 & 90 \\
\hline
\end{tabular}

Extractions were carried out with an adequate volume of solvent, according to the design points of each model, composed of various combinations of the DESs with water and at different $R_{\mathrm{L} / \mathrm{S}}$ as given by the experimental design. All extractions were performed in an oil bath $\left( \pm 0.5^{\circ} \mathrm{C}\right)$ under continuous stirring at $900 \mathrm{rpm}$ for $150 \mathrm{~min}$. Extraction under the optimum conditions, with 70\% (v/v) ethanol, 70\% $(v / v)$ methanol, and $100 \%$ water, was also used in order to compare the total phenol yield by DESs and conventional solvents.

\subsection{Determination of Total Polyphenol}

Total polyphenol yield $\left(Y_{T P}\right)$ was determined using the Folin Ciocalteu reagent and expressed as $\mathrm{mg}$ gallic acid equivalents (GAEs) per g of dry mass. An aliquot of $0.78 \mathrm{~mL}$ of distilled water, $0.02 \mathrm{~mL}$ of sample, and $0.05 \mathrm{~mL}$ of Folin-Ciocalteu reagent were mixed. After exactly $1 \mathrm{~min}, 0.15 \mathrm{~mL}$ of aqueous sodium carbonate $(20 \%$, w/v) was added, and the mixture was allowed to stand at room temperature in the dark, for $60 \mathrm{~min}$. The absorbance was read at $750 \mathrm{~nm}$. The total polyphenol concentration $\left(C_{T P}\right)$ was calculated from a calibration curve, using gallic acid as a standard. Yield in total polyphenols $\left(Y_{T P}\right)$ 
was determined as mg gallic acid equivalents (GAEs) per $\mathrm{g}$ of dry mass (dm), using the following equation:

$$
Y_{T P}\left(\mathrm{mg} \mathrm{GAE}^{-1} \mathrm{dm}\right)=\frac{C_{T P} \times V}{m}
$$

where $V$ is the volume of the extraction medium (L), and $m$ the dry mass of the material (g) [26].

\subsection{Liquid Chromatography-Tandem-Mass Spectrometry (LC-MS/MS)}

For the separation and detection of the compounds of interest, a TSQ Quantum Access MS/MS detector was employed, coupled with a Surveyor LC pump (Thermo Scientific, Waltham, MA, USA). The separation was achieved by a Superspher RP-18 column, $125 \mathrm{~mm} \times 2 \mathrm{~mm}, 4 \mu \mathrm{m}$, at $40^{\circ} \mathrm{C}$, with a $10 \mu \mathrm{L}$ injection loop. The mobile phases utilized were (A) water ( $1 \%$ acetic acid) and (B) methanol (1\% acetic acid). The flow rate was $0.3 \mathrm{~mL} \mathrm{~min}^{-1}$, and a linear gradient elution program was used, as follows: $0 \mathrm{~min}, 5 \% \mathrm{~B}$; $35 \mathrm{~min}, 100 \% \mathrm{~B}$. Mass spectra acquisition was performed in negative ionization mode, capillary temperature $300{ }^{\circ} \mathrm{C}$, sheath gas pressure 30 (arbitrary units), auxiliary gas pressure 15 (arbitrary units), and collision pressure at 1.5 mTorr. The standards we used were oleuropein, hydroxytyrosol, tyrosol, luteolin-7-O-glucoside, and rutin. The quantitation of the compounds was accomplished by external standard calibration curves using the highest intensity fragment that was produced during the collision-induced dissociation (CID) of the selected precursor molecular ion (Table 2).

Table 2. Calibration curves and collision-induced dissociation fragment intensities.

\begin{tabular}{cccccc}
\hline Compounds & $\begin{array}{c}\text { Equation of External } \\
\text { Calibration Curve }\end{array}$ & $\begin{array}{c}\text { Correlation } \\
\text { Coefficient }\end{array}$ & $\begin{array}{c}\text { Molecular } \\
\text { Ion }\end{array}$ & $\begin{array}{c}\text { Fragment } \\
\text { Ion 1 }\end{array}$ & $\begin{array}{c}\text { Fragment } \\
\text { Ion 2 }\end{array}$ \\
\hline & & & $\mathrm{M}-1$ & (quantifier) & (qualifier) \\
\cline { 3 - 5 } Oleuropein & $\mathrm{Y}=4920.6 \mathrm{x}+109,162$ & $\mathrm{r}^{2}=0.9957$ & 539 & 275 & 377 \\
Hydroxytyrosol & $\mathrm{Y}=425.38 \mathrm{x}-1387.8$ & $\mathrm{r}^{2}=0.9994$ & 153 & 122.2 & 123.2 \\
Tyrosol & $\mathrm{y}=1977.8 \mathrm{x}-5810.1$ & $\mathrm{r}^{2}=0.9992$ & 137 & 106.2 & 119.1 \\
Luteolin-7-O-glucoside & $\mathrm{Y}=8567.3 \mathrm{x}+10782$ & $\mathrm{r}^{2}=0.9996$ & 447 & 284 & 285 \\
Rutin & $\mathrm{y}=13,579.286 \mathrm{x}+100,080.787$ & $\mathrm{r}^{2}=0.9984$ & 609 & 300 & 270.9 \\
\hline
\end{tabular}

\subsection{Statistics}

Extractions were repeated twice, and all determinations were performed at least in triplicate. The values obtained were averaged. Experimental design and response surface statistics were performed with JMP ${ }^{\mathrm{TM}}$ Pro 13 (SAS, Cary, NC, USA). Linear and non-linear regressions were performed with Sigma Plot ${ }^{\mathrm{TM}} 12.0$, at least at a $95 \%$ significance level $(p<0.05)$.

\section{Results and Discussion}

\subsection{DES Synthesis}

The number of DESs is continually increasing due to the use of different combinations of donors and acceptors of hydrogen bonds $[27,28]$. Natural products (organic acids, amino acids, sugars, choline, and urea) are preferentially used to synthesize DESs for their low toxicity profile and many other advantages [28]. In this study, three mixtures of glycerol (HBD) with three amino acids (lysine, proline, and arginine) (HBA) were prepared at different molar ratios preceded by a screening of the $\mathrm{R}_{\mathrm{mol}}^{\mathrm{D} / \mathrm{A}}$ for all three DESs.

GL-amino acids mixtures were tested with $R_{\text {mol }}^{\mathrm{D} / \mathrm{A}}$ in the range from 1:1 to 11:1. A transparent mixture was obtained with glycerol:lysine DES (GL-Lys) and glycerol:proline DES (GL-Pro) solvents with all the ratios tested. However, only the (7:1) molar ratio could give a transparent mixture in the case of glycerol:arginine DES (GL-Arg). In order to choose the $\mathrm{R}_{\mathrm{mol}}^{\mathrm{D} / \mathrm{A}}$ in this study, different extractions were performed and the total polyphenol 
yield was considered for all mixtures tested. The selection of the $\mathrm{R}_{\mathrm{mol}}^{\mathrm{D} / \mathrm{A}}$ was based on the highest total phenol value. GL-Arg was synthesized at molar ratio of HBD:HBA (7:1), whereas GL-Lys and GL-Pro were prepared at a (3:1) HBD:HBA molar ratio. Lower $\mathrm{R}_{\text {mol }}^{\mathrm{D} / \mathrm{A}}$ than the ones used in this study resulted in crystallized mixtures in the case of GL-Arg and impracticable DESs in the case of GL-Lys and GL-Pro, due to the high viscosity. Consequently, homogeneous conditions could not be maintained for all DESs, and therefore, the effect of the molar ratio could be an explicative factor of the results. The mixtures were allowed to stand at room temperature for several weeks for stability checking before extraction.

\subsection{Extraction Process Optimization}

It has been reported in many investigations that the variables $R_{L / S}, C_{D E S}$, and $T$ play an important role regarding the extraction of phenolic compounds in general [29]. In order to investigate the combined effect of the independent variables on OLL polyphenol extraction, a BBD process was applied to find the optimized values of the variables $R_{L / S}, C_{\mathrm{DES}}$, and $T$. Fifteen experiments with 3 center points were carried out for different combinations of the variables using statistically designed experiments; the results are shown in Table 3, which includes the design with the experimental and predicted values. The distribution of the data was analyzed for normality using the Shapiro-Wilk test and also for the presence of outliers. The analysis reported zero outliers among all the data, and the normality conditions were only proven for GL-Lys and GL-Pro model values ( $p=0.98, p=0.72$, respectively), whereas a significant $p=0.0147$ was observed for GL-Arg. Bias in the coefficient estimates and standard errors are some of the consequences if the normality assumption is not satisfied. Consequently, this may lead to wrong conclusions regarding the confidence intervals and significance tests [30].

In order to fit a Gaussian distribution, the $Y_{T P}$ values of the GL-Arg model were subjected to a mathematical transformation. One of the statistical goals for transforming data is to obtain symmetrical values that help in conditioning and enabling easier data analysis for subsequent stages [31]. The appropriate transformation is chosen through trial and error until the values have a normal distribution. In this study, the $Y_{T P}$ values of the GL-Arg model were converted using the Box-Cox transformation [32,33]. The transformation has the following form:

$$
Y(\lambda)=\left\{\begin{array}{l}
\frac{y^{\lambda}-1}{\lambda}, \text { if } \lambda \neq 0 \\
\log y, \text { if } \lambda=0
\end{array}\right.
$$

where $Y$ is the transformed value, the parameter lambda $(\lambda)$ defines a particular transformation, which can be a square root when lambda $=0.5$ or natural log when lambda $=0$. The optimal lambda was chosen within a $[-2,2]$ interval with jumps of $1 / 10$ [34]. On the basis of the smallest standard deviation obtained, the optimal value of lambda was found to be at $(-1.2)$. The application of this conversion allowed an insignificant $p$-value ( $p=0.09468)$ for the Shapiro-Wilk test; therefore, it had normalized the data and satisfied the assumption of the test. All subsequent analysis regarding the GL-Arg model was based on the transformed values. 
Table 3. Coded and uncoded Box-Behnken design with the observed and predicted data.

\begin{tabular}{|c|c|c|c|c|c|c|c|c|c|}
\hline \multirow[t]{3}{*}{ Design Point } & \multicolumn{3}{|c|}{ Independent Variables } & \multicolumn{6}{|c|}{ Polyphenols Yield $\left(Y_{T P},{\left.\text { mg GAE } ~^{-1} \mathrm{dm}\right)}\right.$} \\
\hline & \multirow{2}{*}{$R_{L / S}\left(X_{1}, \mathrm{~mL} \mathrm{~g}^{-1}\right)$} & \multirow[t]{2}{*}{$C_{\mathrm{DES}}\left(X_{2}, \% w / v\right)$} & \multirow[t]{2}{*}{$T\left(X_{3},{ }^{\circ} \mathrm{C}\right)$} & \multicolumn{2}{|c|}{ GL-Lys } & \multicolumn{2}{|c|}{ GL-Pro } & \multicolumn{2}{|c|}{ GL-Arg } \\
\hline & & & & Measured & Predicted & Measured & Predicted & Measured * & Predicted * \\
\hline 1 & $50(-1)$ & $90(+1)$ & $60(0)$ & 124.58 & 123.65 & 78.59 & 79.84 & 80.86 & 78.68 \\
\hline 2 & $100(0)$ & $75(0)$ & $60(0)$ & 131.91 & 133.49 & 73.99 & 74.63 & 73.11 & 74.81 \\
\hline 3 & $50(-1)$ & $75(0)$ & $40(-1)$ & 101.50 & 100.40 & 61.87 & 62.28 & 70.10 & 72.61 \\
\hline 4 & $150(+1)$ & $75(0)$ & $80(+1)$ & 191.60 & 139.70 & 87.81 & 87.40 & 114.93 & 112.39 \\
\hline 5 & $50(-1)$ & $75(0)$ & $80(+1)$ & 146.70 & 144.40 & 79.21 & 77.80 & 95.53 & 96.93 \\
\hline 6 & $150(+1)$ & $90(+1)$ & $60(0)$ & 165.21 & 160.89 & 84.39 & 84.63 & 88.07 & 89.81 \\
\hline 7 & $50(-1)$ & $60(-1)$ & $60(0)$ & 92.37 & 96.70 & 67.45 & 67.20 & 75.96 & 74.23 \\
\hline 8 & $100(0)$ & $60(-1)$ & $80(+1)$ & 153.50 & 151.47 & 76.79 & 78.45 & 98.03 & 98.37 \\
\hline 9 & $150(+1)$ & $60(-1)$ & $60(0)$ & 146.00 & 146.93 & 78.86 & 77.61 & 74.91 & 77.10 \\
\hline 10 & $100(0)$ & $90(+1)$ & $40(-1)$ & 120.32 & 122.36 & 72.41 & 70.76 & 74.51 & 74.17 \\
\hline 11 & $100(0)$ & $60(-1)$ & $40(-1)$ & 114.00 & 110.77 & 59.77 & 59.61 & 67.40 & 66.60 \\
\hline 12 & $100(0)$ & $75(0)$ & $60(0)$ & 136.65 & 133.49 & 75.92 & 74.63 & 76.62 & 74.81 \\
\hline 13 & $150(+1)$ & $75(0)$ & $40(-1)$ & 136.26 & 138.60 & 66.48 & 67.89 & 72.62 & 71.14 \\
\hline 14 & $100(0)$ & $75(0)$ & $60(0)$ & 131.91 & 133.49 & 73.99 & 74.63 & 74.69 & 74.81 \\
\hline 15 & $100(0)$ & $90(+1)$ & $80(+1)$ & 177.54 & 180.79 & 86.80 & 86.96 & 107.16 & 107.96 \\
\hline
\end{tabular}


On the basis of the Box-Behnken experimental design model, an empirical relationship expressed by a second-order-polynomial equation with interaction terms was fitted between the obtained experimental design and the input variables. The final equations in terms of coded significant variables and interactions are given in Table 4.

Table 4. Polynomial equations and statistical parameters calculated after implementation of the design.

\begin{tabular}{cccc}
\hline DES & Second Order Polynomial Equations & $\mathbf{r}^{2}$ & $p$ \\
\hline GL-Lys & $Y_{T P}=133.49+10.22 X_{1}+21.86 X_{2}+24.78 X_{3}+10.04 X_{3}^{2}$ & 0.99 & 0.0002 \\
GL-Pro & $Y_{T P}=74.63+4.91 X_{1}+3.80 X_{2}+8.76 X_{3}$ & 0.98 & 0.0006 \\
GL-Arg & $Y_{T P}=0.83+2.64 \times 10^{-4} X_{1}+1.55 \times 10^{-4} X_{2}+9.06 \times 10^{-4} X_{3}+1.98 \times 10^{-4} X_{2}^{2}+4.36 \times 10^{-4} X_{3}^{2}$ & 0.99 & 0.0002 \\
\hline & $X_{1}, X_{2}, X_{3}:$ main effects; $X_{2}^{2}, X_{3}^{2} ;$ quadratic effects. &
\end{tabular}

It is obvious that the models explain $99 \%, 98 \%$, and $99 \%$ in polyphenol extraction yield $\left(r^{2}=0.99\right.$ for GL-Lys, $r^{2}=0.98$ for GL-Pro, and $r^{2}=0.99$ for GL-Arg) and have relatively small amounts of random error or root-mean-square error (RMSE); RMSE $=4.3927$ for GL-Lys, 1.7598 for GL-Pro and 0.0001 for GL-Arg. This leads to the conclusion that the developed models were highly significant.

The lack of fit test is another parameter to support mathematical model validity. This test is used to detect the existence of observations that have a poor fit to the model, even if the overall trend is highly significant [35]. The lack of fit is found to be insignificant when limited observations are outside of the shaded confidence interval region of the actual by-predicted plots. In this study, the models are found to be robust for all cases since all the observations were within the trend of the interval, and a maximum $\mathrm{r}^{2}$ is reached for GL-Lys $\left(\mathrm{r}^{2}=0.9985, p=0.2235\right)$; GL-Pro $\left(\mathrm{r}^{2}=0.9958, p=0.5723\right)$; GL-Arg $\left(\mathrm{r}^{2}=0.9979\right.$, $p=0.2223)$. The coefficient of variation (CV) and the coefficient of correlation between the measured and the predicted values were determined to assess the goodness of the fit of the models. The results (CV, \%, 3.13 GL-Lys, 2.35 GL-Pro, and 0.01 GL-Arg) indicated low CV, which suggests that the deviations between the experimental and the predicted values are low [36]. The low $C V$ values along with the $\mathrm{r}^{2}$ presented in Table 4 are strong indications that the developed models presented adequate reliability and precision.

The measured experimental values under optimum conditions were compared with the predicted values (Table 5). Values from the experiments carried out at the predicted conditions were close to the predicted values in the case of GL-Lys and GL-Arg, and the difference between the two values (experimental and predicted) did not have a practical significance on the good fit of the two models. This small difference could be due to an uncontrolled source of variation during the extraction process (temperature, stirring, etc.) or minor experimental errors, whereas the measured value for GL-Pro was in the range of the predicted values. Considering the entire statistical parameters for model verification, it can be concluded that these results indicated valid and suitable mathematical prediction models for the optimization of polyphenol extraction conditions.

Table 5. Optimal predicted conditions and comparison of experimental and predicted values on the $Y_{T P}$ in all DESs tested. Extractions were performed under stirring (900 rpm) for $150 \mathrm{~min}$.

\begin{tabular}{|c|c|c|c|c|c|}
\hline \multirow[t]{2}{*}{ DES } & \multirow[t]{2}{*}{$\begin{array}{l}\text { Interval Predicted } \\
\text { Values }\left(\mathrm{mg} \mathrm{g}^{-1}\right)\end{array}$} & \multirow[t]{2}{*}{$\begin{array}{l}\text { Observed Value * } \\
\quad\left(\mathrm{mg} \mathrm{g}^{-1}\right)\end{array}$} & \multicolumn{3}{|c|}{ Optimal Conditions } \\
\hline & & & $R_{L / S}\left(\mathrm{~mL} \mathrm{~g}^{-1}\right)$ & $C_{\mathrm{DES}}(\%, w / v)$ & $T\left({ }^{\circ} \mathrm{C}\right)$ \\
\hline GL-Lys & {$[189.58,216.27]$} & $188.39 \pm 0.37$ & 150 & 90 & 80 \\
\hline GL-Pro & {$[86.31,97.00]$} & $95.97 \pm 0.74$ & 150 & 90 & 80 \\
\hline GL-Arg & $\begin{array}{l}{[0.83053,0.8313]^{\mathrm{a}}} \\
{[112.48,129.68]^{\mathrm{b}}}\end{array}$ & $\begin{array}{c}0.83002 \pm 0.47^{\mathrm{a}} \\
100.01 \pm 1.98^{\mathrm{b}}\end{array}$ & 150 & 90 & 80 \\
\hline
\end{tabular}

* Mean \pm standard deviation of triplicate determinations from predicted optimum experiments a: Box-Cox transformed data; $b$ : untransformed data. 
Furthermore, the experimental design enabled the detection of a statistical significance in the quadratic coefficient $X_{3}^{2}(T)$ in two models including GL-Lys and GL-Arg and no cross effect among the variables. Additionally, the obtained results supported that all the variables $\left(X_{1}, X_{2}, X_{3}\right)$ have a significant effect $(p<0.05)$ on the extraction process, as also reported in the literature. This outcome can be visualized through the prediction profilers, which examine the dynamic relationships among all the inputs and outputs simultaneously (Figure 1). The prediction profilers present a general curvature trend of the model profile lines, which illustrates the non-linear responses of the model's effects. An observed increase in every single variable led to an increased response in all three DESs tested.

Desirable $Y_{T P}$ was achieved under $R_{L / S} 150 \mathrm{~mL} \mathrm{~g}^{-1}, C_{\mathrm{DES}} 90 \%, w / v$, and $\mathrm{T} 80^{\circ} \mathrm{C}$ in all three DESs by the desirability function, which produced the maximum overall desirability of $0.992,0.995$, and 0.958 for of GL-Lys, GL-Pro and GL-Arg, respectively.

The findings herein indicated that $R_{L / S}, C_{D E S}$, and $T$ strongly affect the extraction yield of polyphenols from OLL. The $R_{L / S}$ parameter showed a high significance, which is in agreement with previous investigations that have reported the importance of proportionality between the plant material and the solvent in the extraction optimization processes [37]. This key parameter displays a major role in diffusional phenomena, which largely defines the course of extraction and yield. A high extraction yield is usually observed when a larger proportion of liquid phase is used since polyphenols are more solubilized, and a saturation concentration is achieved [38,39].

In this work, the optimal $R_{L / S}\left(150 \mathrm{~mL} \mathrm{~g}^{-1}\right)$ was higher than the values reported in the literature, which usually varied between 10 and $45 \mathrm{~mL} \mathrm{~g}^{-1}$ using DESs and also higher than those of conventional solvents that can reach $120 \mathrm{~mL} \mathrm{~g}^{-1}$ in some investigations $[40,41]$. The observed discrepancies among scientific works regarding the value of the optimum $R_{\mathrm{L} / \mathrm{S}}$ could originate from the variation in the extraction solvent and the experimental conditions (temperature, stirring, time extraction, etc.), the $R_{L / S}$ range selected, and, most likely, the source of polyphenols. Although a common objective is to optimize the extraction of polyphenols, the different extraction conditions could affect the determination of the $R_{L / S}$ optimum value and, consequently, the comparison herein. Similar to $R_{L / S}, C_{\mathrm{DES}}$ showed a high significance regarding the extraction yield of polyphenols from OLLs. The optimum level of $C_{\text {DES }}$ was the same in all three DESs in this study $(90 \% w / v$, Table 5) meaning that the amount of water $\left(C_{\mathrm{w}}\right)$ required to attain a maximum yield is the same in all cases. Water addition to DESs is one of the ways to tailor the physicochemical properties of DESs. Thus, fine-tuning the $C_{\mathrm{W}}$ is central to adjusting DESs properties, such as viscosity and polarity that significantly affect the yield of extraction [42].

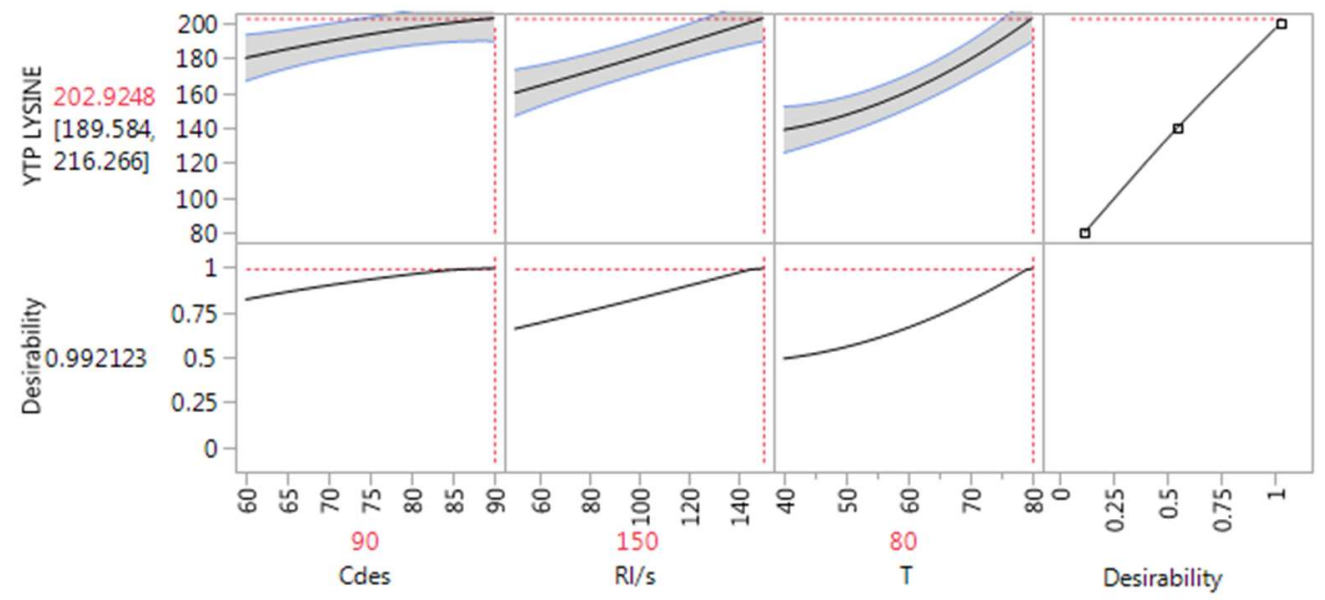

Figure 1. Cont. 

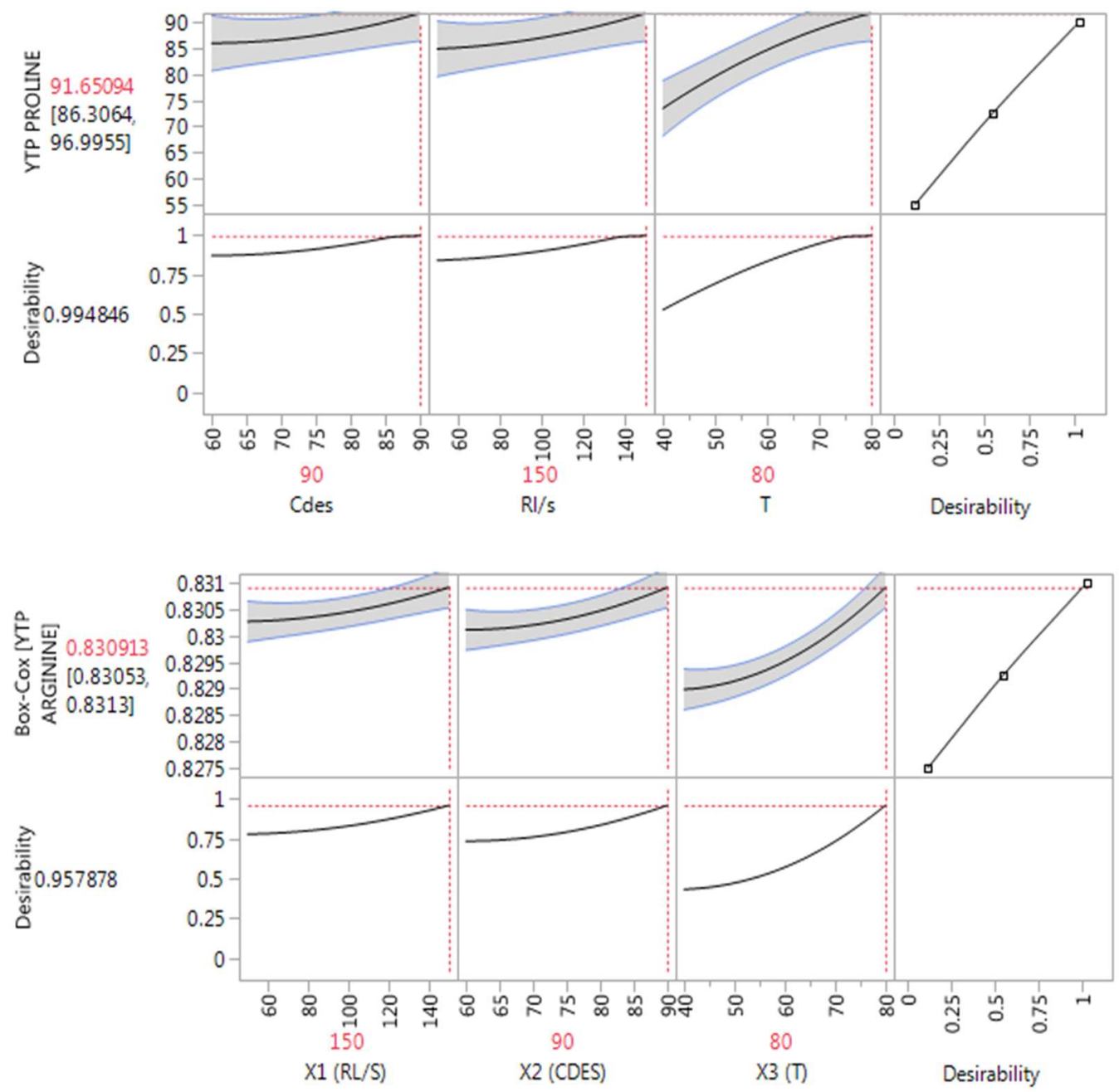

Figure 1. Prediction profilers displaying the overall desirability of GL-Lys, GL-Pro (untransformed data), and GL-Arg DESs (transformed data) along with the optimum $R_{L / S}, C_{\mathrm{DES}}$, and $T$ values.

Recent studies have estimated the optimal $C_{\mathrm{w}}$ to vary from $10 \%$ to $50 \%$ [43], reaching even $63.8 \%$ by Jancheva et al. [44]. It has been noted that water addition to DESs up to a certain point and above the optimal $C_{\mathrm{W}}$ could negatively affect the extraction yield since a large amount of water could cause hydrogen bonds to rupture between HBD and HBA [45].

The outcome with regard to the optimum $C_{W}$ values was found to be $10 \%(v / v)$ for all three DESs tested. This information suggests that all three HBAs tested are equally demanding in water and the differences in the structure and the physicochemical properties of lysine, proline, and arginine did not affect the polarity of the DESs. Such an outcome was rather contradictory with published information that supported differences in $C_{\mathrm{w}}$ using HBAs with different chain lengths. It has been found that the longer the chain, the higher the amount of water required [46]. Hence, the basis behind the efficiency difference of the three DESs herein would be related to another reason such as the $\mathrm{pH}$ of the extraction medium [47]. The alkalinity offered by the amino acids provided a more or less alkaline environment to ionize polyphenols, which may turn them more polar and soluble in the solvent. Lysine, proline, and arginine have the corresponding $\mathrm{pK}_{\mathrm{a}}, 10.57$, 10.47 , and 12.10, respectively. The result expected on the basis of the claimed explanation would be the order of GL-Arg, GL-Lys, and lastly, GL-Pro in terms of solvent efficiency. However, the actual order obtained was GL-Lys, GL-Arg, and lastly, GL-Pro, which only explains the GL-Lys and GL-Pro order. This outcome suggests the existence of another important factor regarding GL-Arg. It has been underlined that increasing the $\mathrm{R}_{\mathrm{mol}}^{\mathrm{D} / \mathrm{A}} \mathrm{up}$ to a certain point could favor polyphenol extraction due to the decrease in viscosity and 
higher diffusivity [48]. Thus, using a higher $\mathrm{R}_{\mathrm{mol}}^{\mathrm{D} / \mathrm{A}}$ of $(7: 1)$ in the case of GL-Arg, compared with a $\mathrm{R}_{\mathrm{mol}}^{\mathrm{D} / \mathrm{A}}$ of $(3: 1)$ in the case of GL-Lys and GL-Pro appears as evidence that the $\mathrm{R}_{\mathrm{mol}}^{\mathrm{D} / \mathrm{A}}$ is of a significant influence on polyphenol extraction optimization processes. Operating in similar optimal extraction conditions, the extraction with GL-Lys yielded 54.83\% and $40.32 \%$ higher $Y_{T P}$, compared with that attained with GL-Pro and GL-Arg, respectively, whereas, extraction with GL-Arg afforded $24.32 \%$ higher $Y_{T P}$, compared with that attained with GL-Pro. This finding suggests the suitability of the GL-Lys for efficient polyphenol extraction, which would possess stronger hydrogen bonding with polyphenols of the plant material regardless of its $\mathrm{R}_{\mathrm{mol}}^{\mathrm{D} / \mathrm{A}}$ and the alkalinity condition, compared with the other solvent essayed $[49,50]$. As a result, it could be concluded that the observed difference in polyphenol yield is mainly attributed to the hydrogen bond acceptors used in this study. Consequently, tailoring the physicochemical properties of the HBAs would be promising in order to enhance polyphenol extraction.

With regard to the temperature effect, an observed favorable effect on polyphenol extraction is reported. Indeed, increasing temperature has shown to lead to an increase in polyphenol extraction yield by improving solubility and hydrolytic reactions [51,52]. This is in accordance with the outcome of the present work. A high significance was observed in all three DESs, and the same optimum extraction temperature $\left(80^{\circ} \mathrm{C}\right)$ was determined. These results showed a similarity with the investigations of Bucić-Kojić et al. [53], who found the highest polyphenol extraction at $80{ }^{\circ} \mathrm{C}$. In addition to this finding, other investigations on kinetics portrayed that diffusion is directly proportional to temperature and follows the Arrhenius law [54,55]. However, at temperatures higher than a certain point, with longer exposure times, it would reduce the polyphenol extraction yield and diversity. That temperature level varies in different scientific works, which probably depends on the extraction solvent and plant material, along with some other related factors as well [56]. Figure 2 illustrates the effect of the experimental variables on the extraction yield through a $3 \mathrm{D}$ plot.

\subsection{Total Polyphenol Analysis}

Total phenolics were determined after $150 \mathrm{~min}$ of extraction. The purpose was to compare the efficiency of the synthesized DESs. The total phenolic content of all DESs extracts was found to be higher than that of ethanol $(70 \% v / v)$, methanol $(70 \% v / v)$, and water occurring in the same extraction conditions (Figure 3). Comparison carried out among the DESs tested informed about the optimum $Y_{T P}$ response and conditions to extract polyphenols from olive leaves. The results exhibited the highest antioxidant activity at similar operational extraction conditions in all three DESs, which were $R_{L / S}=150 \mathrm{~mL} \mathrm{~g}^{-1}$, $C_{\text {DES }}=90 \%$, and $\mathrm{T}=80^{\circ} \mathrm{C}$.

The DESs tested were not equally efficient with respect to conventional solvents. GLLys was found to be the most efficient solvent system for OLL phenol extraction among the DESs tested and the conventional solvents. GL-Arg was slightly better than GL-Pro. The results displayed the $Y_{T P}: 188.39,100.01$, and $95.96 \mathrm{mg} \mathrm{g}^{-1}$ GAE dm for GL-Lys, GL-Arg, and GL-Pro, respectively, compared with 65.95, 62.27, and $52.97 \mathrm{mg} \mathrm{g}^{-1} \mathrm{GAE} \mathrm{dm}$ corresponding to ethanol, methanol, and water $Y_{T P}$, respectively. It should be noted that the extraction with GL-Lys allowed $64 \%, 66.01 \%$, and $71.09 \%$ higher $Y_{T P}$, compared with that attained with ethanol, methanol, and water in the given order. This outcome indicates the efficiency of GL-Lys among the other DESs tested and the conventional solvents as well regarding polyphenol extraction. This result is in accordance with the literature in which a greater extractability with DESs is demonstrated than with conventional solvents [57]. The reason for this difference could be strongly associated with the physicochemical properties of the amino acids used (HBAs), which would interact more or less favorably with glycerol during the preparation process and also with the polyphenols contained in the plant material during the extraction. These intermolecular forces involve hydrogen bonding and even van der Waals interactions [58]. 

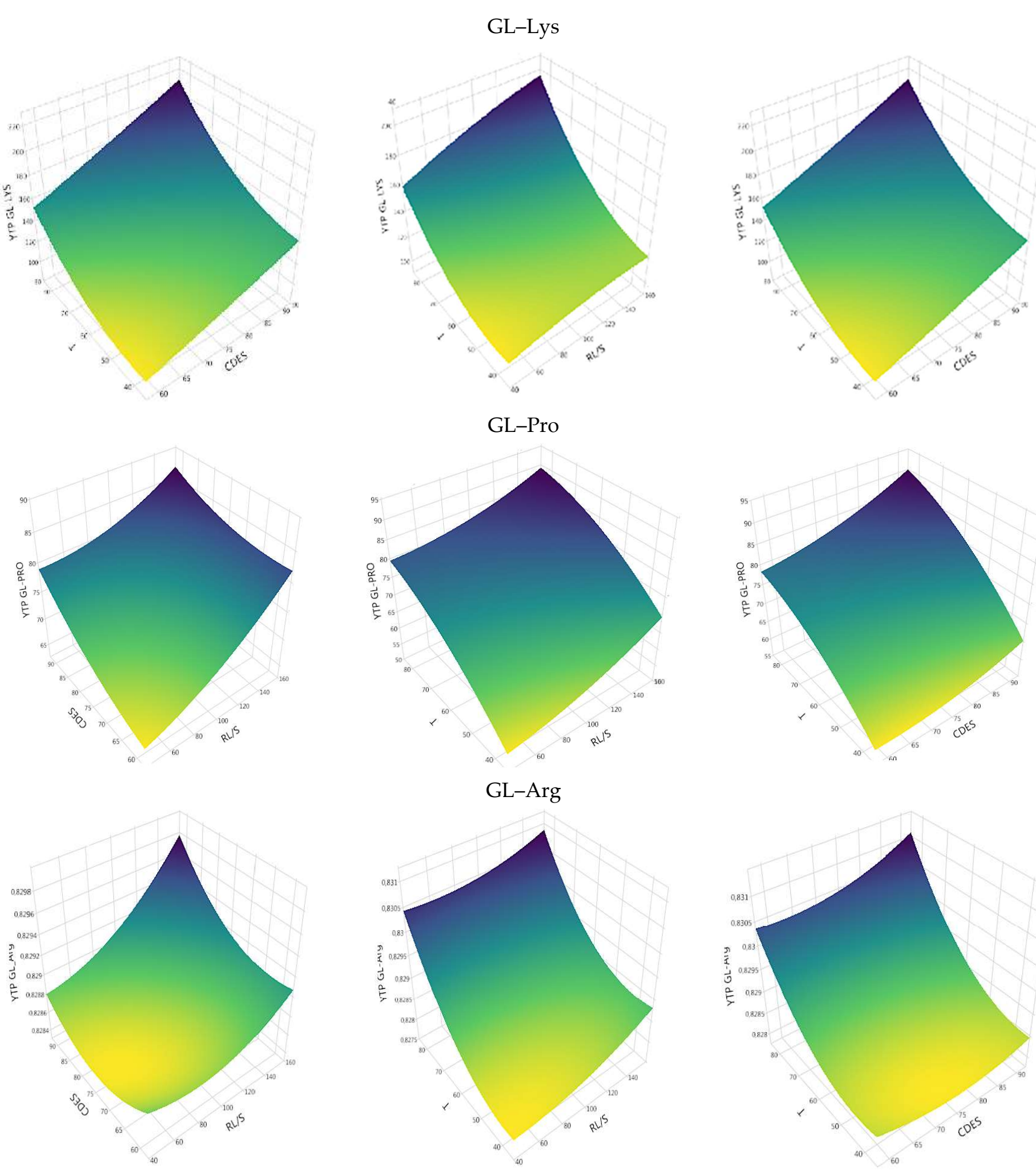

Figure 2. The presented 3D Plots show simultaneous variations in (1) $R_{L / S}$ and $C_{\mathrm{DES}}$, (2) $R_{\mathrm{L} / \mathrm{S}}$ and $T$, and (3) $C_{\mathrm{DES}}$ and $T$ on the $Y_{T P}$ in all three DESs. 


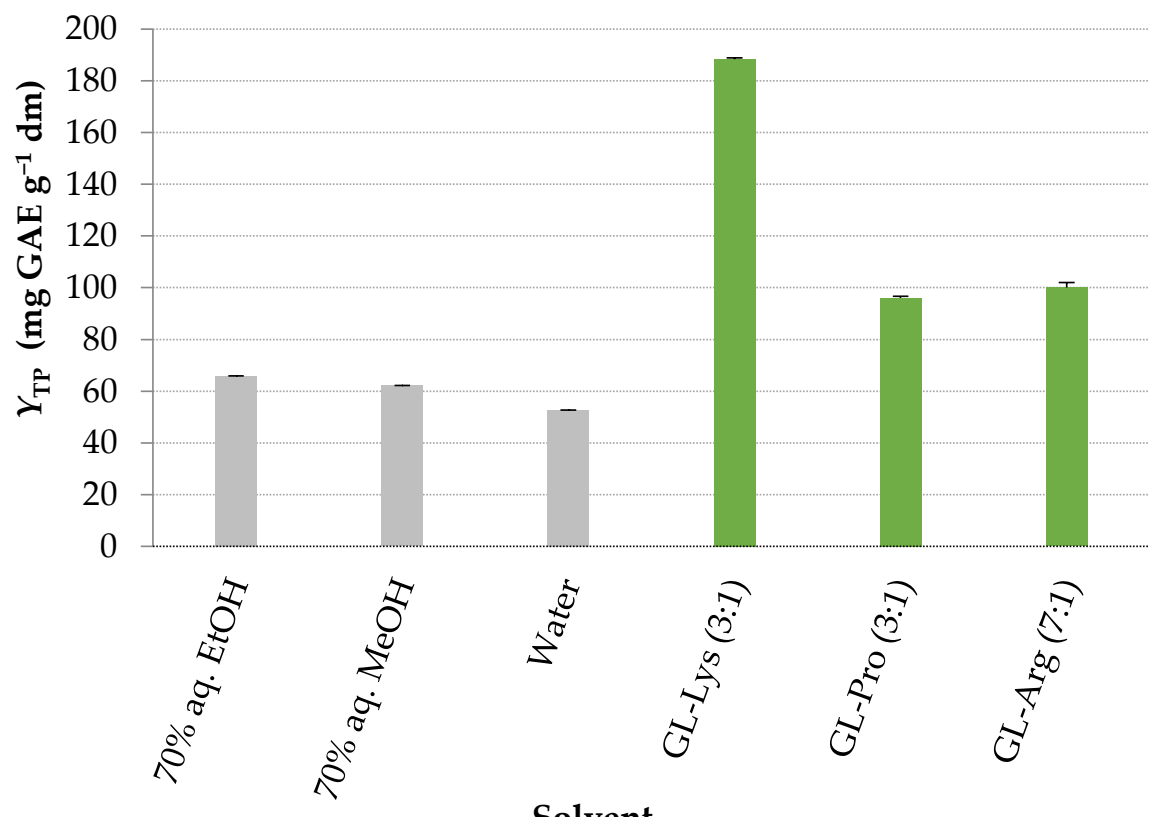

Solvent

Figure 3. Polyphenol extraction yield using conventional and green solvents. Extractions were carried out under optimal conditions $\left(R_{\mathrm{L} / S}=150 \mathrm{~mL} \mathrm{~g}^{-1}, C_{\mathrm{DES}}=90 \%, \mathrm{~T}=80^{\circ} \mathrm{C}\right)$ and stirring $(900 \mathrm{rpm})$ for $150 \mathrm{~min}$.

\subsection{Extract Quantification}

Quantification of polyphenol compounds was carried out by LC-MS/MS for the three DES systems and for 70\% EtOH. The results are presented in Table 6. The analysis of Table 6 demonstrates an overall polyphenol content that is higher in the case of the DESs than that of the ethanolic solution used, which is in agreement with the total phenolic determination performed by Folin Ciocalteu method, as described above. As regards each compound, the results showed important quantitative differences in tyrosol contents with respect to the values reported in the literature, which are in a range of $90 \mu \mathrm{g} \mathrm{g}^{-1}$ to $660 \mu \mathrm{g} \mathrm{g}^{-1}$ [59]. Moreover, the amounts of tyrosol in this study were higher than those of hydroxytyrosol and oleuropein. This outcome is not in accordance with previous investigations that reported an opposite trend [60]. This is likely to be explained by the stability of tyrosol, compared with the other phenolic compounds, and probably the selectivity of the solvents used to extract tyrosol [61]. It has been reported that polyphenols can interact with DESs through hydrogen bonds and therefore increase their stability and solubility in DESs whose composition (HBD/HBA) plays a critical role in the extraction efficiency [62]. Additionally, a high and linear correlation was found between tyrosol content and the total phenol content (TPC) in all DES extracts under study (Figure 4). Many factors have been mentioned in relation to the variation in phenolic content of olive leaf extracts such as the extraction procedure, hydric deficiency, salinity, fertilization, geographical zone, sampling time, light exposition, frost stress, leaves age, the olive variety, bacteria, and fungi [63,64].

The amounts of hydroxytyrosol from the OLL extracts in the present study were found to be lower than most of the values found by other authors [65-67], but higher than the amounts recorded in Brahmi et al. (2013) [68]. Similarly, the values of oleuropein content were lower than expected with GL-Lys extract and GL-Arg extract in which oleuropein was not found, but close to some published values in the case GL-Pro and the ethanolic solution [69] and even higher with respect to the findings in [70,71]. Furthermore, the results of this study exhibited a simultaneous increase in hydroxytyrosol concentration and a decrease in oleuropein concentration, which is attributed to the degradation of oleuropein into hydroxytyrosol due to the chemical and enzymatic reactions during olive leaves processing [72]. Regarding luteolin-7-O-glucoside and rutin, their concentration values were within the range of the upper and lower values reported in the literature [73-78]. It 
should be noted that the observed differences in the content of the phenolic compounds herein are attributed to the above-mentioned factors.

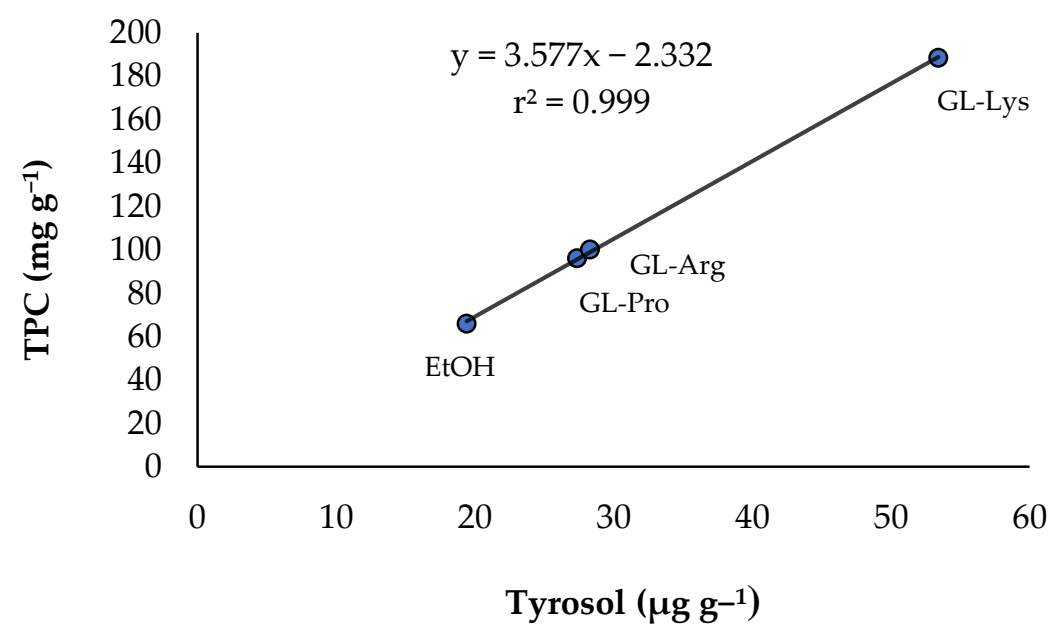

Figure 4. Relationship between total phenolic content and tyrosol concentration.

Table 6. Quantification of phenolic compounds in dry olive leaf extracts $\left(\mu g \mathbf{g}^{-1}\right)$.

\begin{tabular}{cccccc}
\hline Solvent & \multicolumn{4}{c}{ Phenolic Compounds Concentrations $\mu \mathbf{g ~ g}^{-1}$ ) } \\
\hline & Tyrosol & Hydroxytyrosol & Oleuropein & $\begin{array}{c}\text { Luteolin-7-O- } \\
\text { Glucoside }\end{array}$ & Rutin \\
\hline 70\% aq.EtOH & $19398.64 \pm 362.12$ & $205.78 \pm 9.11$ & $7381.03 \pm 52.14$ & $1418.64 \pm 28.74$ & $714.63 \pm 18.25$ \\
GL-Lys & $53420.23 \pm 1135.12$ & $1687.95 \pm 2.4$ & n.d & $1377.14 \pm 17.25$ & $286.69 \pm 0.69$ \\
GL-Pro & $27358.48 \pm 175.71$ & $231.95 \pm 9.8$ & $7908.10 \pm 59.45$ & $997.84 \pm 80.51$ & $463.06 \pm 4.92$ \\
GL-Arg & $28312.65 \pm 445.30$ & $2686.44 \pm 7.9$ & n.d & $1564.97 \pm 63.98$ & $268.59 \pm 33.82$ \\
\hline
\end{tabular}

Values are given as a mean of six measurements, followed by standard deviation. n.d: not detected.

\section{Conclusions}

A new set of deep eutectic solvents, with glycerol as a hydrogen bond donor and lysine, proline, and arginine as hydrogen bond acceptors were synthesized and tested for their extraction capacity for antioxidant polyphenolic compounds from olive leaves (Olea europaea L.). To our knowledge, this is the first time these novel DES solvents are tested on olive leaves. Box-Behnken design was applied to optimize the extraction conditions related to liquid/solid ratio, the concentration of DESs, and extraction temperature $\left(R_{L / S}, C_{\mathrm{DES}}\right.$, and $T$, respectively). The optimal conditions for the best extraction of total phenols were predicted to be $R_{L / S}, 150 \mathrm{~mL} \mathrm{~g}^{-1}, \mathrm{C}_{\mathrm{DES}} 90(\%, w / v)$ and $T 80^{\circ} \mathrm{C}$. The predicted total phenol yield, under optimal conditions $\left(188.39,100.01\right.$, and $95.97 \mathrm{mg} \mathrm{g}^{-1} \mathrm{GAE} \mathrm{dm}$, corresponding to glycerol-lysine, glycerol-arginine, and glycerol-proline solvent systems, respectively), were matched quite closely by the experimental values obtained. Glycerollysine DES was found to be the most effective in extracting phenolic compounds from olive leaf compared with glycerol-arginine DES and glycerol-proline and even to conventional solvents-namely, ethanol $(70 \% v / v)$, methanol $(70 \% v / v)$, and water. The results showed that the extraction with glycerol-lysine permitted $40.32 \%, 54.83 \%, 64 \%, 66.01 \%$, and $71.09 \%$ higher total phenol yield $\left(Y_{T P}\right)$, compared with that reached with glycerol-arginine, glycerol-proline, $70 \%$ ethanol, $70 \%$ methanol, and water solvents, respectively. Moreover, liquid chromatography-tandem-mass spectrometry analyses proved the high extraction capacity of glycerol-lysine DES and showed a selective behavior toward the quantified phenolic compounds. Overall, the DESs used in this study revealed a favorable extraction for tyrosol with excessive amounts in comparison with previous investigations, but more or less important differences were observed concerning hydroxytyrosol, oleuropein, luteolin7-O-glucoside, and rutin. The new DESs, designed, synthesized, and tested in this study, 
were proven to be successful in general on the extraction of antioxidant polyphenolics from olive leaves, a by-product of a very important industry-olive oil production.

Author Contributions: Conceptualization, N.L.-S., S.G. and D.P.M.; methodology, N.L.-S., S.G., D.P.M. and H.A.; software, H.A. and S.G.; validation, N.L.-S., S.G., D.P.M., A.C. and A.M.; formal analysis, H.A., S.L. and A.K.; investigation, H.A., S.G. and S.L.; resources, N.L.-S., S.G. and D.P.M.; data curation, H.A. and S.G.; writing-original draft preparation, H.A., S.G. and N.L.-S.; writingreview and editing, H.A., S.G., D.P.M., N.L.-S., A.C. and A.M.; visualization, H.A.; supervision, S.G., D.P.M. and N.L.-S.; project administration, S.G.; funding acquisition, S.G. All authors have read and agreed to the published version of the manuscript.

Funding: This research received no external funding.

Conflicts of Interest: The authors declare no conflict of interest.

\section{Nomenclature}

$\begin{array}{ll}C_{\mathrm{DES}} & \text { Proportion of DES/water }(\%: w / v) \\ C_{\mathrm{w}} & \text { Water concentration }(\%, v / v) \\ R L / S & \text { Liquid-to-solid ratio }\left(\mathrm{mL} \mathrm{g}^{-1}\right) \\ \mathrm{R}_{\mathrm{mol}}^{\mathrm{D} / \mathrm{A}} \text { HBD:HBA } & \text { Molar ratio (dimensionless) } \\ T & \text { Temperature }\left({ }^{\circ} \mathrm{C}\right) \\ Y_{T P} & \text { Yield in total polyphenols }\left(\mathrm{mg} \mathrm{GAE} \mathrm{G}^{-1}\right)\end{array}$

$\begin{array}{ll}\text { Abbreviations } \\ \text { ANOVA } & \text { Analysis of variance } \\ \text { Arg } & \text { Arginine } \\ \text { CV } & \text { Coefficient of variance } \\ \text { DES } & \text { Deep eutectic solvent } \\ \text { Dm } & \text { Dry mass }(\mathrm{g}) \\ \text { GAE } & \text { Gallic acid equivalents } \\ \text { GL } & \text { Glycerol } \\ \text { HBA } & \text { Hydrogen bond acceptor } \\ \text { HBD } & \text { Hydrogen bond donor } \\ \text { LTTMs } & \text { Low-transition temperature mixtures } \\ \text { Lys } & \text { Lysine } \\ \text { OLL } & \text { Olive leaves } \\ \text { Pro } & \text { Proline }\end{array}$

\section{References}

1. Lebersorger, S.; Schneider, F. Discussion on the methodology for determining food waste in household waste composition studies. J. Waste Manag. 2011, 31, 1924-1933. [CrossRef]

2. Cicatiello, C.; Franco, S.; Pancino, B.; Blasi, E. The value of food waste: An exploratory study on retailing. J. Retail. Consum. Serv. 2016, 30, 96-104. [CrossRef]

3. Eriksson, M.; Strid, I.; Hansson, P.A. Carbon footprint of food waste management options in the waste hierarchy-a Swedish case study. J. Clean. Prod. 2015, 93, 115-125. [CrossRef]

4. Papargyropoulou, E.; Lozano, R.; Steinberger, J.K.; Wright, N.; Ujang, Z.B. The food waste hierarchy as a framework for the management of food surplus and food waste. J. Clean. Prod. 2014, 76, 106-115. [CrossRef]

5. Mirabella, N.; Castellani, V.; Sala, S. Current options for the valorization of food manufacturing waste: A review. J. Clean. Prod. 2014, 65, 28-41. [CrossRef]

6. Bonilla, J.; Vargas, F.C.; Gomes de Oliveira, T.; Makishi, G.L.D.A.; Sobral, P.J.D.A. Recent patents on the application of bioactive compounds in food: A short review. Curr. Opin. Food Sci. 2015, 5, 1-7. [CrossRef]

7. Abaza, L.; Taamalli, A.; Nsir, H.; Zarrouk, M. Olive Tree (Olea europeae L.) Leaves: Importance and Advances in the Analysis of Phenolic Compounds. Antioxidants 2015, 4, 682-698. [CrossRef] [PubMed]

8. Rahmanian, N.; Jafari, S.M.; Wani, T.A. A comprehensive review on the bioactive profile, dehydration, Extraction and application of the bioactive components of olive leaves. Trends Food Sci. Technol. 2015, 42, 150-172. [CrossRef]

9. Dias, R.; Oliveira, H.; Fernandes, I.; Simal-Gandara, J.; Perez-Gregorio, R. Recent advances in extracting phenolis compounds from food and their use in disease prevention and cosmetics. Crit. Rev. Food Sci. Nutr. 2021, 61, 1130-1151. [CrossRef] 
10. Niki, E.; Yoshida, Y.; Saito, Y.; Noguchi, N. Lipid peroxidation: Mechanisms, inhibition, and biological effects. Biochem. Biophys. Res. Commun. 2005, 338, 668-676. [CrossRef]

11. Caleja, C.; Barros, L.; Antonio, A.L.; Oliveira, M.B.P.P.; Ferreira, I.C.F.R. A comparative study between natural and synthetic antioxidants: Evaluation of their performance after incorporation into biscuits. Food Chem. 2017, 216, 342-346. [CrossRef]

12. Sindhi, V.; Gupta, V.; Sharma, K.; Bhatnagar, S.; Kumari, R.; Dhaka, N. Potential applications of antioxidants. J. Pharm. Res. 2013, 7, 828-835. [CrossRef]

13. Mollica, A.; Zenginb, G.; Stefanuccia, A.; Ferrantea, C.; Menghinia, L.; Orlandoa, G.; Brunettia, L.; Locatellia, M.; Dimmitoa, M.P.; Novellinoc, E.; et al. Nutraceutical potential of Corylus avellana daily supplements for obesity and related dysmetabolism. $J$. Funct. Foods 2018, 47, 562-574. [CrossRef]

14. Dykes, L.; Rooney, L.L.; Waniska, R.D.; Rooney, W.L. Phenolic Compounds and Antioxidant Activity of Sorghum Grains of Varying Genotypes. J. Agric. Food Chem. 2005, 53, 6813-6818. [CrossRef]

15. Do, Q.D.; Angkawijaya, A.E.; Tran-Nguyen, P.L.; Huynh, L.H.; Soetaredjo, F.E.; Ismadji, S.; Ju, Y.-H. Effect of extraction solvent on total phenol content, total flavonoids content, and antioxidant activity of Limnophila aromatic. J. Food Drug Anal. 2013, 22, 296-302. [CrossRef]

16. Pena-Pereira, F.; Namieśnik, J. Ionic Liquids and Deep Eutectic Mixtures: Sustainable Solvents for Extraction Processes. Chem. Sustain. Chem. 2014, 7, 1784-1800. [CrossRef]

17. Shishov, A.; Bulatov, A.; Locatelli, M.; Carradori, S.; Andruch, V. Application of deep eutectic solvents in analytical chemistry. Michrochem. J. 2017, 135, 33-38. [CrossRef]

18. Merone, G.M.; Tartaglia, A.; Rosato, E.; D’Ovidio, C.; Kabir, A.; Ulusoy, H.I.; Savini, F.; Locatelli, M. Ionic Liquids in Analytical Chemistry: Applications and Recent Trends. Curr. Anal. Chem. 2021, 17, 1340-1355. [CrossRef]

19. Abbott, P.; Boothby, D.; Capper, G.; Davies, D.L.; Rasheed, R.K. Deep Eutectic Solvents Formed between Choline Chloride and Carboxylic Acids: Versatile Alternatives to Ionic Liquids. J. Am. Chem. Soc. 2004, 126, 9142-9147. [CrossRef]

20. Paiva, A.; Craveiro, R.; Aroso, I.; Martins, M.; Reis, R.L.; Duarte, A.R.C. Natural Deep Eutectic Solvents - Solvents for the 21st Century. ACS Sustain. Chem. Eng. 2014, 2, 1063-1071. [CrossRef]

21. Cunha, S.C.; Fernandes, J. Extraction techniques with deep eutectic solvents. Trends Anal. Chem. 2018, 105, 225-239. [CrossRef] [PubMed]

22. Bezerra, M.A.; Santelli, R.E.; Oliveira, E.P.; Villar, L.S.; Escaleira, L.A. Response surface methodology (RSM) as a tool for optimization in analytical chemistry. Talanta 2008, 76, 965-977. [CrossRef]

23. Garg, L.K.; Reddy, V.S.; Sait, S.S.; Krishnamurthy, T.; Vali, S.J.; Reddy, A.M. Quality by Design: Design of Experiments Approach Prior to the Validation of a Stability-Indicating HPLC Method for Montelukast. Chromatographia 2013, 76, 1697-1706. [CrossRef]

24. Yetilmezsoya, K.; Demirel, S.; Vanderbei, R.J. Response surface modeling of Pb (II) removal from aqueous solution by Pistacia vera L.: Box-Behnken experimental design. J. Hazard. Mater. 2009, 171, 551-562. [CrossRef]

25. Joseph Davidson, M.; Balasubramanian, K.; Tagore, G.R.N. Surface roughness prediction of flow-formed AA6061 alloy by design of experiments. J. Mater. Process. Technol. 2008, 202, 41-46. [CrossRef]

26. Karakashov, B.; Grigorakis, S.; Loupassaki, S.; Makris, D.P. Optimisation of polyphenol extraction from Hypericum perforatum (St. John's Wort) using aqueous glycerol and response surface methodology. J. Appl. Res. Med. Arom. Plants 2015, 2, 1-8. [CrossRef]

27. García, A.; Rodríguez-Juan, E.; Rodríguez-Gutiérrez, G.; Rios, J.J.; Fernández-Bolaños, J. Extraction of phenolic compounds from virgin olive oil by deep eutectic solvents (DESs). Food Chem. 2016, 197, 554-561. [CrossRef]

28. Dai, Y.; Van Spronsen, J.; Witkamp, G.J.; Verpoorte, R.; Hae Choi, Y. Natural Deep Eutectic Solvents as New Potential Media for Green Technology. Anal. Chim. Acta 2013, 766, 61-68. [CrossRef]

29. Xia, B.; Yan, D.; Bai, Y.; Xie, J.; Cao, Y.; Liao, D.; Lin, L. Determination of phenolic acids in Prunella vulgaris L. a safe and green extraction method using alcohol-based deep eutectic solvents. Anal. Methods 2015, 7, 9354-9364. [CrossRef]

30. Glass, G.V.; Peckham, P.D.; Sanders, J.R. Consequences of failure to meet assumptions underlying the fixed effects analyses of variance and covariance. Educ. Res. Rev. 2012, 42, 237-288. [CrossRef]

31. Tsai, A.C.; Liou, M.; Simak, M.; Cheng, P.E. On hyperbolic transformations to normality. Comput. Stat. Data Anal. 2017, 115, 250-266. [CrossRef]

32. Malaeb, Z.A. A SAS code to correct for non-normality and non-constant variance in regression and anova models using the Box-Cox method of power transformation. Environ. Monit. Assess. 1997, 47, 255-273. [CrossRef]

33. Asar, Ö.; Ilk, O.; Dag, O. Estimating Box-Cox power transformation parameter via goodness of fit tests. Commun. Stat. Simul. Comput. 2014, 46, 91-105. [CrossRef]

34. Ishak, N.A.M.; Ahmad, S. Estimating Optimal Parameter of Box-Cox Transformation in Multiple Regression with Non-normal Data. In Regional Conference on Science, 1st ed.; Technology and Social Sciences (RCSTSS 2016), Yacob, N.A., Mohd Noor, N.A., Mohd Yunus, N.Y., Lob Yussof, R., Zakaria, S.A.K.Y., Eds.; Springer: Singapore, 2018; pp. 1039-1046. [CrossRef]

35. Bischoff, W.; Miller, F. Optimal designs which are efficient for lack of fit tests. Ann. Stat. 2006, 34, 2015-2025. [CrossRef]

36. Ramić, M.; Vidović, S.; Zeković, Z.; Vladić, J.; Cvejin, A.; Pavlić, A. Modeling and optimization of ultrasound-assisted extraction of polyphenolic compounds from Aronia melanocarpa by-products from filter-tea factory. Ultrason. Sonochem. 2014, 23, 360-368. [CrossRef] [PubMed] 
37. Rakotondramasy-Rabesiaka, L.; Havet, J.L.; Porte, C.; Fauduet, H. Estimation of effective diffusion and transfer rate during the protopine extraction process from Fumaria offcinalis L.. Sep. Purif. Technol. 2010, 76, 126-131. [CrossRef]

38. Katsampa, P.; Valsamedou, E.; Grigorakis, S.; Makris, D. A green ultrasound-assisted extraction process for the recovery of antioxidant polyphenols and pigments from onion solid wastes using Box-Behnken experimental design and kinetics. Ind. Crop. Prod. 2015, 77, 535-543. [CrossRef]

39. Chakroun, D.; Grigorakis, S.; Loupassaki, S.; Makris, D.P. Enhanced-performance extraction of olive (Olea europaea) leaf polyphenols using L-lactic acid/ammonium acetate deep eutectic solvent combined with $\beta$ _cyclodextrin: Screening, optimisation, temperature effects and stability. Biomass Convers. Biorefinery 2021, 11, 1125-1136. [CrossRef]

40. Vetal, M.D.; Lade, V.G.; Rathod, V.K. Extraction of ursolic acid from Ocimum sanctum by ultrasound: Process intensification and kinetic studies. Chem. Eng. Process. Process. Intensif. 2013, 69, 24-30. [CrossRef]

41. Dedousi, M.; Mamoudaki, V.; Grigorakis, S.; Makris, D.P. Ultrasound-assisted extraction of polyphenolic antioxidants from olive (Olea europaea) leaves using a novel glycerol/sodium-potassium tartrate low-transition temperature mixture (LTTM). Environments 2017, 4, 31. [CrossRef]

42. Dai, Y.; Rozema, E.; Verpoorte, R.; Choi, Y.H. Application of natural deep eutectic solvents to the extraction of anthocyanins from Catharanthus roseus with high extractability and stability replacing conventional organic solvents. J. Chromatogr. A 2016, 1434, 50-56. [CrossRef] [PubMed]

43. Dai, Y.; van Spronsen, J.; Witkamp, G.J.; Verpoorte, R.; Choi, Y.H. Ionic liquids and deep eutectic solvents in natural products research: Mixtures of solids as extraction solvents. J. Nat. Prod. 2013, 76, 2162-2173. [CrossRef] [PubMed]

44. Jancheva, M.; Grigorakis, S.; Loupassaki, S.; Makris, D.P. Optimised extraction of antioxidant polyphenols from Satureja thymbra using newly designed glycerol-based natural low-transition temperature mixtures (LTTMs). J. Appl. Res. Med. Aromat. Plants 2017, 6, 31-40. [CrossRef]

45. Dai, Y.; Witkamp, G.J.; Verpoorte, R.; Choi, Y.H. Tailoring properties of natural deep eutectic solvents with water to facilitate their applications. Food Chem. 2015, 187, 14-19. [CrossRef] [PubMed]

46. Slim, Z.; Jancheva, M.; Grigorakis, S.; Makris, D.P. Polyphenol extraction from Origanum dictamnus using low-transition temperature mixtures composed of glycerol and organic salts: Effect of organic anion carbon chain length. Chem. Eng. Commun. 2018, 205, 1494-1506. [CrossRef]

47. Ajila, C.M.; Brar, S.K.; Verma, M.; Tyagi, R.D.; Godbout, S.; Valero, J.R. Extraction and Analysis of Polyphenols: Recent trends Crit. Rev. Biotechnol. 2011, 31, 227-249. [CrossRef] [PubMed]

48. Bi, W.; Tian, M.; Row, K.H. Evaluation of alcohol-based deep eutectic solvent in extraction and determination of flavonoids with response surface methodology optimization. J. Chromatogr. A 2013, 1285, 22-30. [CrossRef] [PubMed]

49. Fanali, C.; Della Posta, S.; Dugo, L.; Gentili, A.; Mondello, L.; De Gara, L. Choline-chloride and betaine-based deep eutectic solvents for green extraction of nutraceutical compounds from spent coffee ground. J. Pharm Biomed. Anal. 2020, 189, 113421-113445. [CrossRef] [PubMed]

50. Rente, D.; Paiva, A.; Duarte, A.R. The Role of Hydrogen Bond Donor on the Extraction of Phenolic Compounds from Natural Matrices Using Deep Eutectic Systems. Molecules 2021, 26, 2336. [CrossRef] [PubMed]

51. Gironi, F.; Piemonte, V. Temperature and solvent effects on polyphenol extraction process from chestnut tree wood. Chem. Eng. Res. Des. 2011, 89, 857-862. [CrossRef]

52. Vergara-Salinas, J.R.; Peérez-Jimeénez, J.; Torres, J.L.; Agosin, E.; Peérez-Correa, J.R. Effects of Temperature and Time on Polyphenolic Content and Antioxidant Activity in the Pressurized Hot Water Extraction of Deodorized Thyme (Thymus vulgaris). J. Agric. Food Chem. 2012, 60, 10920-10929. [CrossRef] [PubMed]

53. Bucić-Kojić, A.; Planinić, M.; Tomas, S.; Bilić, M.; Veli, D. Study of solid-liquid extraction kinetics of total polyphenols from grape seeds. J. Food Eng. 2007, 81, 236-242. [CrossRef]

54. Cacace, J.E.; Mazza, G. Mass transfer process during extraction of phenolic compounds from milled berries. J. Food Eng. 2003, 59, 379-389. [CrossRef]

55. Pedreschi, F.; Travisany, X.; Reyes, C.; Troncoso, E.; Pedreschi, E. Kinetics of extraction of reducing sugar during blanching of potato slices. J. Food Eng. 2009, 91, 443-447. [CrossRef]

56. Ho, C.H.; Cacace, J.E.; Mazza, G. Mass transfer during pressurized low polarity water extraction of lignans from flaxseed meal. $J$. Food Eng. 2008, 89, 64-71. [CrossRef]

57. Kottaras, P.; Koulianos, M.; Makris, D.P. Low-transition temperature mixtures (LTTMs) made of bioorganic molecules: Enhanced extraction of antioxidant phenolics from industrial cereal solid wastes. Recycling 2017, 2, 3. [CrossRef]

58. Francisco, M.; van den Bruinhorst, A.; Kroon, M.C. Low-transition-temperature mixtures (LTTMs): A new generation of designer solvents. Angew. Chem. Int. Ed. 2013, 52, 3074-3085. [CrossRef]

59. Özcan, M.M.; Matthäus, B. A review: Benefit and bioactive properties of olive (Olea europaea L.) leaves. Eur. Food Res. Technol. 2016, 243, 89-99. [CrossRef]

60. Benavente-García, O.; Castillo, J.; Lorente, J.; Ortuño, A.; Del Rio, J.A. Antioxidant activity of phenolics extracted from Olea europaea L. leaves. Food Chem. 2000, 68, 457-462. [CrossRef]

61. Karkovíc Markovíc, A.; Toríc, J.; Barbaríc, M.; JokobušícBrala, C. Hydroxytyrosol, Tyrosol and Derivatives and Their Potential Effects on Human Health. Molecules 2019, 24, 2001. [CrossRef] 
62. Dai, Y.; Verpoorte, R.; Choi, Y.H. Natural deep eutectic solvents providing enhanced stability of natural colorants from safflower (Carthamus tinctorius). Food Chem. 2014, 159, 116-121. [CrossRef] [PubMed]

63. Quirantes-Piné, R.; Zurek, G.; Barrajón-Catalán, E.; Bäßmann, C.; Micol, V.; Segura-Carretero, A.; Fernández-Gutiérrez, A. A metabolite-profiling approach to assess the uptake and metabolism of phenolic compounds from olive leaves in SKBR3 cells by HPLC-ESI-QTOF-MS. J. Pharm. Biomed. Anal. 2013, 72, 121-126. [CrossRef]

64. Talhaoui, N.; Taamalli, A.; Gómez-Caravaca, A.M.; Fernández-Gutiérrez, A.; Segura-Carretero, A. Phenolic compounds in olive leaves: Analytical determination, biotic and abiotic influence, and health benefits. Int. Food Res. 2015, 77, 92-108. [CrossRef]

65. Vinha, A.F.; Ferreres, F.; Silva, B.M.; Valentão, P.; Gonçalves, A.; Pereira, J.A.; Oliveira, M.B.; Seabra, R.M.; Andrade, P.B. Phenolic profiles of Portuguese olive fruits (Olea europaea L.): Influences of cultivar and geographical origin. Food Chem. 2005, 89, 561-568. [CrossRef]

66. Cittan, M.; Çelik, A. Development and Validation of an Analytical Methodology Based on Liquid Chromatography-Electrospray Tandem Mass Spectrometry for the Simultaneous Determination of Phenolic Compounds in Olive Leaf Extract. J. Chromatogr. Sci. 2018, 56, 336-343. [CrossRef]

67. Ahmad-Qasem, M.H.; Cánovas, J.; Barrajón-Catalán, E.; Micol, V.; Cárcel, J.A.; García-Pérez, J.V. Kinetic and compositional study of phenolic extraction from olive leaves (var. Serrana) by using power ultrasound. Innov. Food Sci. Emerg. Technol. 2013, 17, 120-129. [CrossRef]

68. Brahmi, F.; Mechri, B.; Dhibi, M.; Hammami, M. Variations in phenolic compounds and antiradical scavenging activity of Olea europaea leaves and fruits extracts collected in two different seasons. Ind. Crops Prod. 2013, 49, 256-264. [CrossRef]

69. Ortega-García, F.; Peragón, J. Phenol Metabolism in the Leaves of the Olive Tree (Olea europaea L.) cv. Picual, Verdial, Arbequina, and Frantoio during Ripening. J. Agric. Food Chem. 2010, 58, 12440-12448. [CrossRef] [PubMed]

70. Lee, O.H.; Lee, B.Y.; Lee, J.; Lee, H.B.; Son, J.Y.; Park, C.S.; Shetty, K.; Kim, Y.C. Assessment of phenolics-enriched extract and fractions of olive leaves and their antioxidant activities. Bioresour. Technol. 2009, 100, 6107-6113. [CrossRef] [PubMed]

71. Afaneh, I.; Yateem, H.; Al-Rimawi, F. Effect of Olive Leaves Drying on the Content of Oleuropein. Am. J. Anal. Chem. 2015, 6, 246-252. [CrossRef]

72. Yuan, J.J.; Wang, C.Z.; Ye, Z.; Tao, R.; Zhang, Y.S. Enzymatic Hydrolysis of Oleuropein from Olea europea (Olive) Leaf Extract and Antioxidant Activities. Molecules 2015, 20, 2903-2921. [CrossRef] [PubMed]

73. Meirinhos, J.; Silva, B.M.; Valentão, P.; Seabra, R.M.; Pereira, J.A.; Dias, A.; Andrade, P.B.; Ferreres, F. Analysis and quantification of flavonoidic compounds from Portuguese olive (Olea europaea L.) leaf cultivars. Nat. Prod. Res. 2005, 19, 189-195. [CrossRef] [PubMed]

74. Liakopoulos, G.; Karabourniotis, G. Boron deficiency and concentrations and composition of phenolic compounds in Olea europaea leaves: A combined growth chamber and field study. Tree Physiol. 2005, 25, 307-315. [CrossRef] [PubMed]

75. Savournin, C.; Baghdikian, B.; Elias, R.; Dargouth-Kesraoui, F.; Boukef, K.; Balansard, G. Rapid High-Performance Liquid Chromatography Analysis for the Quantitative Determination of Oleuropein in Olea europaea Leaves. J. Agric. Food Chem. 2001, 49, 618-621. [CrossRef] [PubMed]

76. Japón-Luján, R.; Luque-Rodríguez, J.M.; Luque De Castro, M.D. Dynamic ultrasound-assisted extraction of oleuropein and related biophenols from olive leaves. J. Chromatogr. A 2006, 1108, 76-82. [CrossRef] [PubMed]

77. Goulas, V.; Exarchou, V.; Troganis, A.N.; Psomiadou, E.; Fotsis, T.; Briasoulis, E.; Gerothanassis, I.P. Phytochemicals in olive-leaf extracts and their antiproliferative activity against cancer and endothelial cells. Mol. Nutr. Food Res. 2009, 53, 600-608. [CrossRef]

78. Talhaoui, N.; Vezza, T.; Gómez-Caravaca, A.M.; Fernández-Gutiérrez, A.; Gálvez, J.; Segura-Carretero, A. Phenolic compounds and in vitro immunomodulatory properties of three Andalusian olive leaf extracts. J. Funct. Foods 2016, 22, 270-277. [CrossRef] 